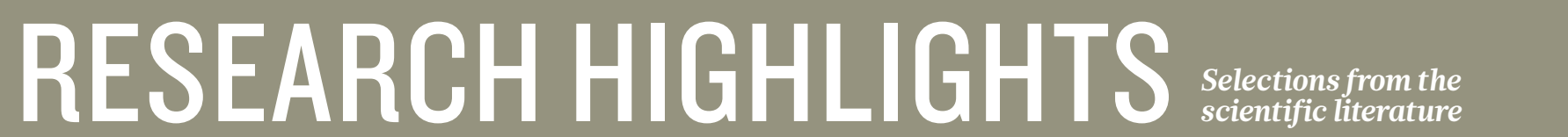

CHEMISTRY

\section{Controlling the coffee-ring effect}

A drop of coffee usually leaves a ring-shaped stain when it dries on a surface, but researchers have now used light to control the shape of the deposit left behind.

In the coffee-ring effect, particles flow to a droplet's edge as the liquid evaporates, forming the ring. To change this, Damien Baigl and Manos Anyfantakis from the Ecole Normale Supérieure in Paris added surfactants to polystyrene nanoparticles suspended in water droplets. The polarity of surfactant molecules changed when exposed to ultraviolet light, sticking the nanoparticles to the top of the droplet. This stopped the particles moving to the edge as liquid evaporated, so that they formed a disc instead of a ring.

The technique could prove useful for controlling deposits when droplets that contain particles dry, such as in ink-jet printing.

Angew. Chem. Int. Ed. http://doi. org/f2vh3d (2014)

\section{EVOLUTION}

\section{Insect natural history traced}

Insects emerged some 480 million years ago, eventually becoming the most diverse animal group.

Details about the early evolution of the more than 900,000 known insect species are still contentious. Bernhard Misof at the Alexander Koenig Zoological Research Museum in Bonn, Germany, and his colleagues determined the

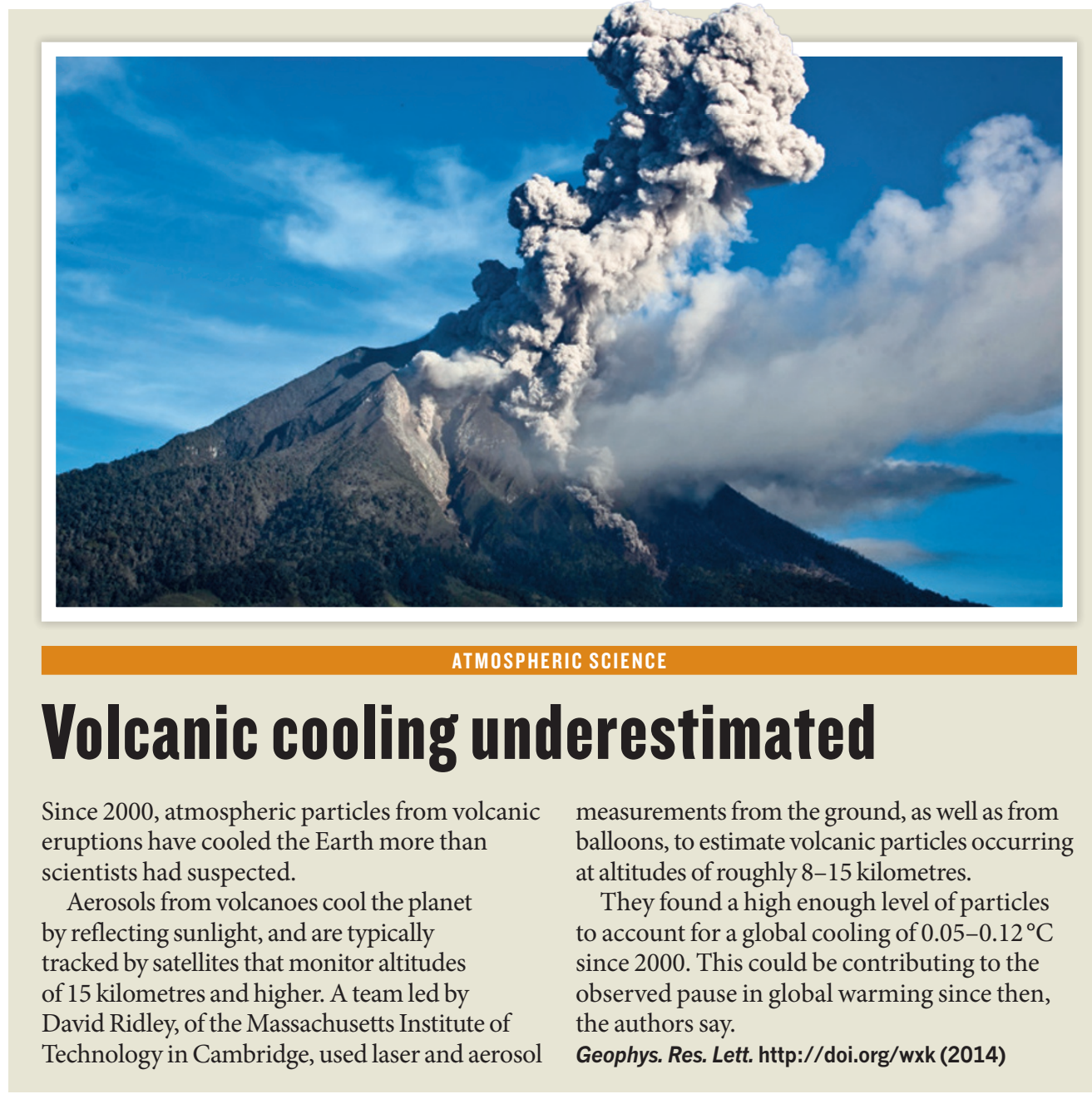

evolutionary relationships of all 30 orders of insects by analysing fossil and molecular data. The first insects evolved in marine or coastal habitats and took to land at around the same time as plants appeared, some 440 million years ago. Flying insects appeared around 40 million years later, followed by a boom in insect diversity.

All the major lineages of insects that are alive today were in existence by about 375 million years ago, giving the animals plenty of time to diversify even more (pictured). Science 346, 763-767 (2014)

\section{Cell decoys capture toxins}

Specially designed lipid sacs bind to deadly bacterial toxins in infected mice, helping the animals to clear the pathogen.

Certain bacteria release toxins that kill host cells by binding to the cell membrane. Eduard Babiychuk at the University of Bern, Switzerland, and his team created liposomes - artificial spheres made of cholesterol and other lipids found in cell
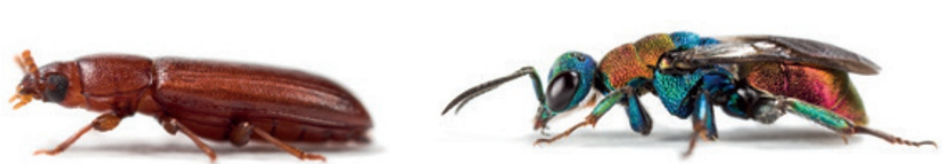

membranes - to act as decoys and bind the toxins.

In a lab dish, the liposomes captured various bacterial toxins, protecting human cells. In mice infected with Streptococcus pneumoniae and Staphyloccocus aureus, the liposomes stopped the animals getting blood poisoning, whereas untreated animals died in under two days.

Such liposomes, already in use as drug carriers, could help to treat certain bacterial infections, the team says.

Nature Biotechnol. http://doi.org/ wxm (2014)

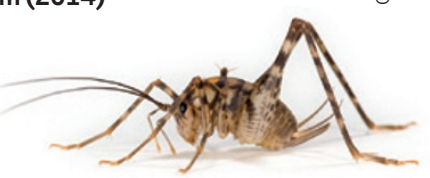

